\title{
Photocatalytic Activity of Toluene under UV-LED Light with $\mathrm{TiO}_{2}$ Thin Films
}

\author{
Thammasak Rojviroon, ${ }^{1}$ Apirat Laobuthee, ${ }^{2}$ and Sanya Sirivithayapakorn ${ }^{1}$ \\ ${ }^{1}$ Department of Environmental Engineering, Faculty of Engineering, Kasetsart University, Bangkok 10900, Thailand \\ ${ }^{2}$ Department of Materials Engineering, Faculty of Engineering, Kasetsart University, Bangkok 10900, Thailand
}

Correspondence should be addressed to Sanya Sirivithayapakorn, fengsys@ku.ac.th

Received 27 August 2012; Revised 25 September 2012; Accepted 25 September 2012

Academic Editor: Vincenzo Augugliaro

Copyright (C) 2012 Thammasak Rojviroon et al. This is an open access article distributed under the Creative Commons Attribution License, which permits unrestricted use, distribution, and reproduction in any medium, provided the original work is properly cited.

Titanium dioxide $\left(\mathrm{TiO}_{2}\right)$ and ferric-doped $\mathrm{TiO}_{2}\left(\mathrm{Fe}-\mathrm{TiO}_{2}\right)$ thin films were synthesized on the surface of 304 stainless steel sheets using a simplified sol-gel preparation method. The $\mathrm{Fe}-\mathrm{TiO}_{2}$ thin films were prepared with weight-to-volume ratios of $\mathrm{Fe}^{3+} / \mathrm{TiO}_{2}$ of $0.3 \%, 0.5 \%$, and $0.7 \%$, respectively. The crystalline phase structures of the prepared $\mathrm{TiO}_{2}$ and $\mathrm{Fe}-\mathrm{TiO}_{2}$ thin films were entirely anatase. The measured optical band gaps of the $\mathrm{TiO}_{2}, 0.3 \% \mathrm{Fe}-\mathrm{TiO}_{2}, 0.5 \% \mathrm{Fe}-\mathrm{TiO}_{2}$, and $0.7 \% \mathrm{Fe}-\mathrm{TiO}_{2}$ thin films were 3.27, 3.28, 3.22, and $2.82 \mathrm{eV}$, respectively. The grain sizes and other physical properties of the prepared thin films were also reported. The kinetics of the photocatalytic processes under a UV-LED light source could be explained by the Langmuir-Hinshelwood kinetic model with the specific rates of $2.00 \times 10^{-3}, 4.00 \times 10^{-3}, 5.00 \times 10^{-3}$, and $7.00 \times 10^{-3} \mathrm{~min}^{-1} \mathrm{~mW}^{-1}$, for $\mathrm{TiO}_{2}, 0.3 \% \mathrm{Fe}-\mathrm{TiO}_{2}, 0.5 \%$ $\mathrm{Fe}-\mathrm{TiO}_{2}$, and $0.7 \% \mathrm{Fe}_{-} \mathrm{TiO}_{2}$, respectively. An increase in $\mathrm{Fe}^{3+}$ dopant concentration could enhance the photocatalytic activity of toluene decomposition as a result of lower optical band gaps, smaller grain size, and higher surface area.

\section{Introduction}

Titanium dioxide is a photocatalyst that has been used extensively due to its good photocatalytic activity, relatively low toxicity, and low cost. Among the common crystalline forms of $\mathrm{TiO}_{2}$-anatase, rutile and brookite-anatase are generally recognized as the most active photocatalyst owing to its smaller particle size, high surface area-to-volume ratio, and narrow band gap. Applications of $\mathrm{TiO}_{2}$ can be found in various practices including sterilization and microorganism disinfection (especially bacteria and viruses), hazardous waste remediation as well as treatment and purification of water and air [1-12]. One of the most widely used methods to fabricate $\mathrm{TiO}_{2}$ nanoparticles is the sol-gel technique [9, 13-15]. This coating technique has been applied to various materials, such as metal, plastic, silicon, and polymer $[6,16]$. In this research, we fabricated both $\mathrm{TiO}_{2}$ and $\mathrm{Fe}-\mathrm{TiO}_{2}$ thin films using a simplified sol-gel technique modified from Eshaghi et al. [9]. This technique has many advantages such as low processing temperature, the possibility of coating large area substrates, and not requiring complicated equipment.
In this study, we modified this technique by using different solvents for sol-gel preparation, modifying the calcination temperature scheme, adding Fe dopant in the sol-gel process, and reducing the stirring time and dip coating speed. A wide range of physical properties of the thin films were systematically compared and reported. The crystalline phases on the $\mathrm{TiO}_{2}$ thin films were identified by the X-ray diffraction (XRD) technique. The surface morphology was investigated using atomic force microscopy (AFM). Other physical properties were also investigated including BET surface area as well as adhesion and corrosion testing.

In this research, we selected UV-light emitting diodes (UV-LEDs) with a peak wavelength of $365 \mathrm{~nm}$ as the light source. The UV-LED is safer than mercury vapor lamps and UVC germicidal lamps that have been widely used in photocatalytic processes, since the UV-LED does not contain trace amounts of toxic mercury. Moreover, the UV-LED is durable and cheap, consumes less energy, and generates lower heat $[17,18]$.

The objectives of this research were to develop the technique of $\mathrm{TiO}_{2}$ thin film preparation and improve 
TABLE 1: Surface properties of dip-coated $\mathrm{TiO}_{2}$ thin films on stainless steel substrates.

\begin{tabular}{|c|c|c|c|c|}
\hline \multirow{2}{*}{ Surface properties } & \multicolumn{4}{|c|}{ Catalysts } \\
\hline & $\mathrm{TiO}_{2}$ & $0.3 \% \mathrm{Fe}-\mathrm{TiO}_{2}$ & $0.5 \% \mathrm{Fe}-\mathrm{TiO}_{2}$ & $0.7 \% \mathrm{Fe}-\mathrm{TiO}_{2}$ \\
\hline Crystalline phase & Anatase & Anatase & Anatase & Anatase \\
\hline Optical band gap (eV) & 3.27 & 3.28 & 3.22 & 2.82 \\
\hline Grain size $(\mathrm{nm})$ & $20-250$ & $20-150$ & $50-180$ & $30-100$ \\
\hline RMS average roughnesses (nm) & 18.30 & 11.92 & 18.40 & 12.92 \\
\hline Apparent surface area $\left(\mathrm{m}^{2} \mathrm{~m}^{-2}\right)\left({ }^{1}\right)$ & 1.08 & 1.06 & 1.11 & 1.09 \\
\hline Total weight of $\mathrm{TiO}_{2}$ on substrate $\left(\mathrm{g} \mathrm{m}^{-2}\right)\left({ }^{2}\right)$ & 0.15 & 0.15 & 0.15 & 0.14 \\
\hline Total apparent surface area per total weight of $\mathrm{TiO}_{2}\left(\mathrm{~m}^{2} \mathrm{~g}^{-1}\right)\left({ }^{3}\right)=\left({ }^{1}\right) /\left({ }^{2}\right)$ & 7.13 & 7.07 & 7.66 & 7.81 \\
\hline BET surface area $\left(\mathrm{m}^{2} \mathrm{~g}^{-1}\right)$ & 36.98 & 21.61 & 32.57 & 42.73 \\
\hline \multicolumn{5}{|l|}{ Adherence } \\
\hline Classification & $4 \mathrm{~B}$ & $4 \mathrm{~B}$ & $4 \mathrm{~B}$ & $4 \mathrm{~B}$ \\
\hline Rank & Good & Good & Good & Good \\
\hline Corrosion test & $\checkmark$ & $\checkmark$ & $\checkmark$ & $\checkmark$ \\
\hline
\end{tabular}

$\checkmark$ : no visible damage.

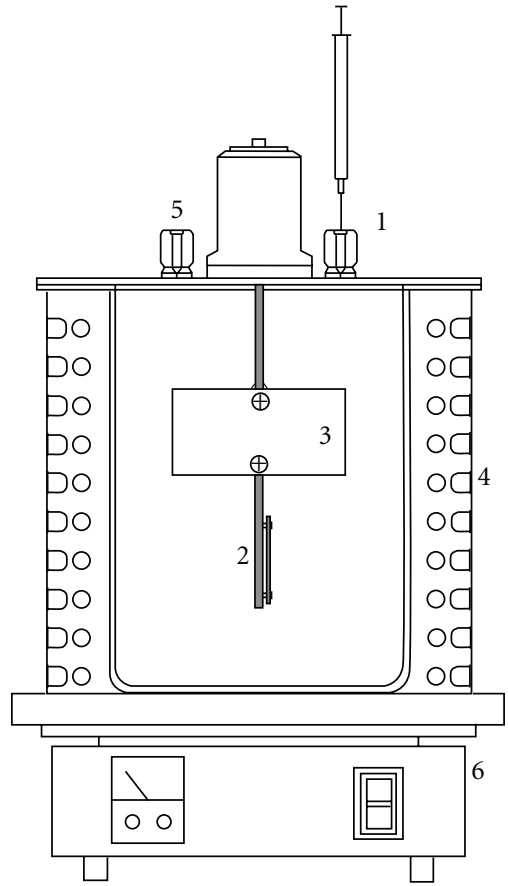

Figure 1: Schematic diagram of the photoreactor used for the degradation of toluene. 1: sampling port, 2: glass reactor, 3: coated stainless steel impeller, 4: UV-LED light source, 5: motor, 6: power supply.

TABLE 2: L-H parameters obtained in the photocatalytic degradation of toluene.

\begin{tabular}{lccc}
\hline Catalyst & $k\left(\mathrm{~mol} \cdot \mathrm{m}^{-3} \cdot \mathrm{min}^{-1}\right)$ & $K\left(\mathrm{~m}^{3} \cdot \mathrm{mol}^{-1}\right)$ & $k K\left(\mathrm{~min}^{-1}\right)$ \\
\hline $\mathrm{TiO}_{2}$ & $1.83 \times 10^{-4}$ & 109.29 & 0.02 \\
$0.3 \% \mathrm{Fe}-\mathrm{TiO}_{2}$ & $2.00 \times 10^{-4}$ & 200.00 & 0.04 \\
$0.5 \% \mathrm{Fe}-\mathrm{TiO}_{2}$ & $2.02 \times 10^{-4}$ & 247.52 & 0.05 \\
$0.7 \% \mathrm{Fe}-\mathrm{TiO}_{2}$ & $2.57 \times 10^{-4}$ & 272.37 & 0.07 \\
\hline
\end{tabular}

the photocatalytic efficiency of $\mathrm{TiO}_{2}$ thin films by adding $\mathrm{Fe}$ dopant. Using the prepared $\mathrm{TiO}_{2}$ thin films and UV-LED as

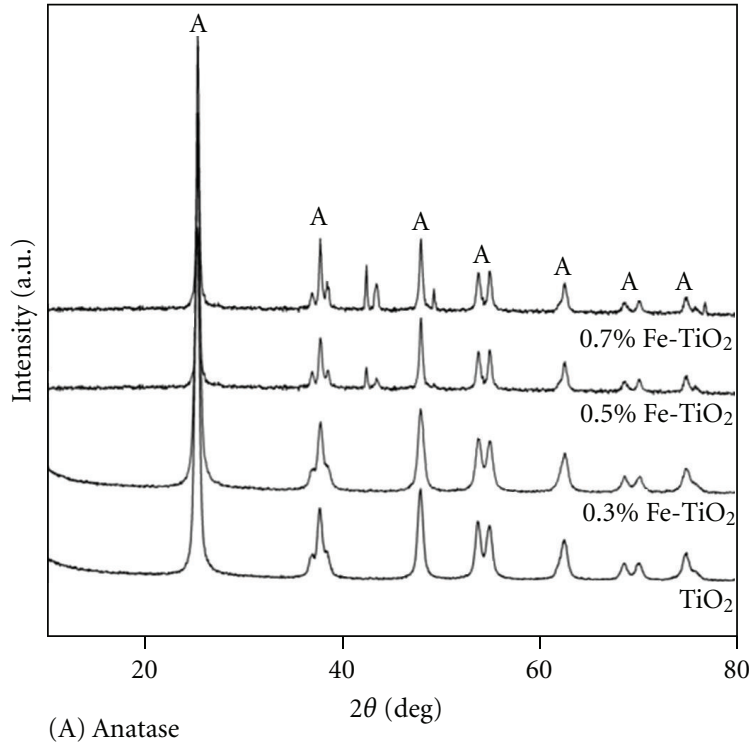

Figure 2: XRD patterns of crystalline $\mathrm{TiO}_{2}$.

the light source, the degradation efficiencies and kinetics of toluene in the photocatalytic process in a batch reactor are reported.

\section{Experimental}

2.1. Preparation of $\mathrm{TiO}_{2}$ and $\mathrm{Fe}-\mathrm{TiO}_{2}$ Thin Films. The $\mathrm{TiO}_{2}$ and $\mathrm{Fe}-\mathrm{TiO}_{2}$ thin films were prepared with an acid-catalyzed sol-gel dip-coating on the surface of 304 stainless steel sheets $(40.0 \times 85.0 \times 0.3 \mathrm{~mm})$ using titanium tetraisopropoxide $(\mathrm{Ti}$ $\left[\mathrm{OCH}\left(\mathrm{CH}_{3}\right)_{2}\right]_{4}$, TTIP) as a precursor. For the preparation of the $\mathrm{TiO}_{2}$ thin films, the sol-gel solution was prepared by mixing TTIP with isopropanol with a volume ratio of $1: 15$. For the preparation of the $\mathrm{Fe}-\mathrm{TiO}_{2}$ thin films, iron (III) nitrate $\left(\mathrm{Fe}\left(\mathrm{NO}_{3}\right)_{3} 9 \mathrm{H}_{2} \mathrm{O}\right)$ was added to the TTIP and isopropanol solution with weight-to-volume ratios of 




Figure 3: XRF spectrum of $0.3 \% \mathrm{Fe}-\mathrm{TiO}_{2}$ on a glass slide.

$\mathrm{Fe}^{3+} / \mathrm{TiO}_{2}$ of $0 \%, 0.3 \%, 0.5 \%$, and $0.7 \%$. Afterwards, the $\mathrm{pH}$ of the solutions was adjusted to between 2 and 3 using concentrated hydrochloric acid. The solutions were stirred at room temperature in a closed chamber with constant flow of $\mathrm{N}_{2}$ gas for $1 \mathrm{~h}$ and left to dry at room temperature for $24 \mathrm{~h}$ before being ready to use. The thin films were developed on the surfaces by dip-coating the sol-gel solutions at a rate of $9 \mathrm{~mm} / \mathrm{min}$ in a sealed chamber. During this dip-coating process, the chamber was continuously flushed with nitrogen gas to minimize contact with air. The first layer of coating was heated at $100^{\circ} \mathrm{C}$ to prepare the surface for coating the next layer. After coating the first layer, the same dip-coating processes were carried out layer by layer for the subsequent layers. The second and third layers were heat-treated in an oven at 250 and $500^{\circ} \mathrm{C}$ for $1 \mathrm{~h}$, respectively. After the heat treatment, the coated substrates were gradually cooled down in the oven for $1 \mathrm{~h}$ before being taken out and left to cool down at normal room temperature. All of the stainless steel sheets were weighed before and after coating each layer.

2.2. Characterization of the Thin Films. The nanostructure and optical band gap of the thin films were determined by XRD (Bruker model D8 Advance) and UV-Vis spectrometer in the wavelength range $290-800 \mathrm{~nm}$ (Lambda 650 PerkinElmer), respectively. The surface morphology of the thin films was investigated by AFM (Asylum Research MFP-3D$\mathrm{BIO})$. The grain size was measured directly from crosssectional AFM images at the base of each grain. The apparent surface areas of the thin films were determined with Gwyddion software, version 2.22 (http:/gwyddion.net/). To confirm the composition of thin films, elemental analysis was performed using X-ray Fluorescence (Horiba XGT-2000 W). The X-ray tube and current parameters were set to $50 \mathrm{kV}$ and $1 \mathrm{~mA}$. Since the substrates for thin films were 304 stainless steel sheets, we measured $\mathrm{Fe}-\mathrm{TiO}_{2}$ glass slides coated by the same procedure.

Both $\mathrm{TiO}_{2}$ and $\mathrm{Fe}-\mathrm{TiO}_{2}$ nanoparticle powders for the BET surface area analyses were prepared by heating the solgel solutions at $100^{\circ} \mathrm{C}$ for $1 \mathrm{~h}$ and then at $500^{\circ} \mathrm{C}$ for $1 \mathrm{~h}$. The BET surface area of the powders was calculated from the $\mathrm{N}_{2}$ adsorption isotherm (BELSORP-max). The crosshatch adhesion between the thin films and the substrates was examined using the ASTM method D3359B-08 [21]. Using a method modified from Shankar et al. [22], the corrosion resistance of the thin films was tested by dipping the coated substrates in nitric acid and sodium hydroxide at concentrations of 1, 5, and 10 molar percent, respectively, for $5 \mathrm{~min}$.

2.3. Photocatalytic Activity Test. The photocatalytic activities of the thin films were evaluated by the degradation of toluene. A cylindrical glass batch reactor of $1100 \mathrm{~mL}$ capacity was used as a reaction vessel (photoreactor). The reactor was placed in a UV-LED light source chamber that contained 500 UV-LED light bulbs. The average intensity in the photoreactor was $1000 \mathrm{~mW} \cdot \mathrm{m}^{-2}$. The top cover plates of the reactor were made from stainless steel. Two coated stainless steel sheets were mounted onto the stainless steel shaft that was powered by the motor (Figure 1) to provide both mixing and photoreactions. The concentration of toluene vapor was measured with a gas chromatograph (Model Shimadzu GC-2014). The gas chromatograph was equipped with an Intercap- 1 capillary column of $30 \mathrm{~m}$ length, $0.25 \mathrm{~mm}$ inner diameter, and $0.4 \mu \mathrm{m}$ film thickness. The operating conditions of the GC were as follows: injector temperature $120^{\circ} \mathrm{C}$, detector temperature $200^{\circ} \mathrm{C}$, column temperature $150^{\circ} \mathrm{C}$, and a sample volume of $40 \mu \mathrm{L}$.

The desired amount of toluene was injected as gas phase into the reactor. A sample of the initial concentration of toluene was taken for measurement just before the UVLED light sources were turned on. The concentration of toluene was recorded with reaction time throughout the photocatalytic activity test. The measured concentrations of toluene from the photocatalytic activity test were corrected using the results from control experiments carried out in the dark (with catalyst) and those carried out under UV-LED light only (without catalyst) before the kinetics calculations.

\section{Results and Discussion}

3.1. Characterization of $\mathrm{TiO}_{2}$ Thin Films. The XRD pattern showed prominent peaks occurring at $2 \theta=25.2^{\circ}$ (Figure 2 ). The strong peaks confirm the presence of only anatase phase in the $\mathrm{TiO}_{2}$ thin films [23-25]. From the XRD pattern, increasing the $\mathrm{Fe}^{3+}$ dopant concentration in $\mathrm{TiO}_{2}$ thin films does not affect the phase of $\mathrm{TiO}_{2}$. Similar to the finding of $\mathrm{Yu}$ et al. [26], other $\mathrm{Fe}_{x} \mathrm{TiO}_{y}$ phases were not found in the XRD pattern mainly because of the low Fe-doping concentration and the similar radius of $\mathrm{Fe}^{3+}(0.64 \AA)$ and $\mathrm{Ti}^{4+}(0.68 \AA)$. Thus, the $\mathrm{Fe}^{3+}$ ions can enter into the crystal structure of titania and locate at interstices or replace some of the lattice sites of $\mathrm{TiO}_{2}$, forming an iron-titanium solid solution $[26,27]$. A similar finding was also reported previously in several studies, which prepared the thin films by the solgel, chemical vapor deposition (CVD) and electrophoretic deposition (EPD) techniques, and where the films were annealed at temperatures ranging from 400 to $600^{\circ} \mathrm{C}[9,24$, 25,28 .

Owing to the limitations of the XRD technique, XRF was used to analyze the composition of the thin films qualitatively. The XRF spectrum of $0.3 \% \mathrm{Fe}^{-\mathrm{TiO}_{2}}$ coated on a glass slide is shown in Figure 3. The appearance of the Fe peak implies that Fe was successfully doped in the $\mathrm{TiO}_{2}$ thin films. 


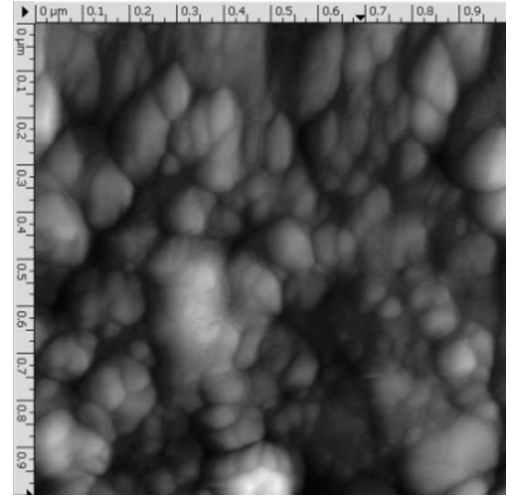

(a)



(c)

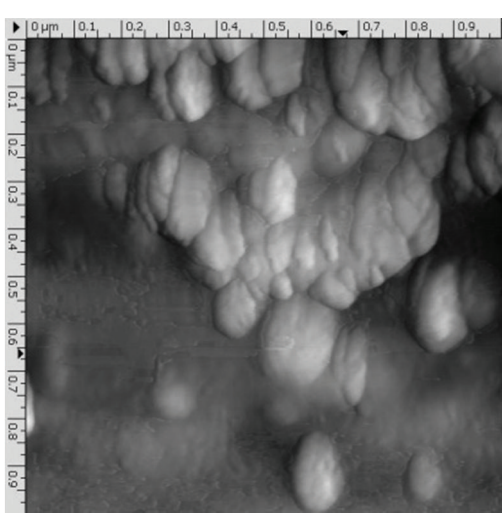

(b)

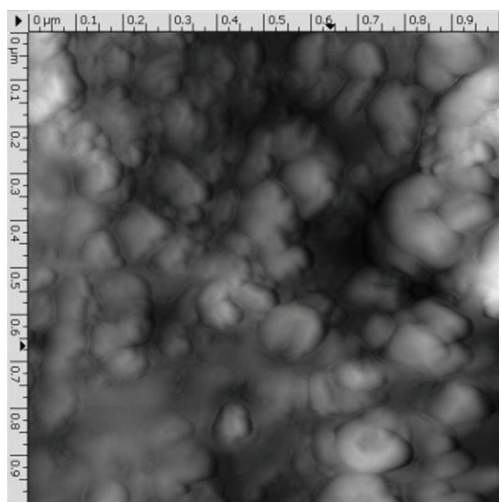

(d)

Figure 4: 2D AFM images of $\mathrm{TiO}_{2}$ thin films on stainless steel substrate: (a) $\mathrm{TiO}_{2}$; (b) $0.3 \% \mathrm{Fe}-\mathrm{TiO}_{2} ;$ (c) $0.5 \% \mathrm{Fe}-\mathrm{TiO}{ }_{2}$; (d) $0.7 \% \mathrm{Fe}-\mathrm{TiO}$.

TABLE 3: Specific rate comparisons with other studies for the photocatalytic degradation of toluene.

\begin{tabular}{lcccc}
\hline Catalyst & $\begin{array}{c}k K\left(\mathrm{~min}^{-1}\right) \\
\left({ }^{1}\right)\end{array}$ & $\begin{array}{c}\text { Coated area }\left(\mathrm{m}^{2}\right) \\
\left({ }^{2}\right)\end{array}$ & $\begin{array}{c}\text { Intensity } \\
\left(\mathrm{mW} \cdot \mathrm{m}^{-2}\right) \\
(3)\end{array}$ & $\begin{array}{c}\text { Specific rate }\left(\mathrm{min}^{-1} \cdot \mathrm{mW}^{-1}\right) \\
\left({ }^{1}\right) /\left({ }^{2}\right) \times\left({ }^{3}\right)\end{array}$ \\
\hline $\mathrm{Ag} / \mathrm{TiO}_{2}$ & 0.04 & 0.12 & 5800 & $5.74 \times 10^{-5}$ \\
\hline $\mathrm{TiO}_{2}$ & 0.15 & 0.03 & 20,950 & $2.39 \times 10^{-4}$ \\
\hline $\mathrm{TiO}_{2}$ & 0.02 & & & $2.00 \times 10^{-3}$ \\
$0.3 \% \mathrm{Fe}-\mathrm{TiO}_{2}$ & 0.04 & 0.01 & 1000 & $4.00 \times 10^{-3}$ \\
$0.5 \% \mathrm{Fe}-\mathrm{TiO}_{2}$ & 0.05 & & & $5.00 \times 10^{-3}$ \\
$0.7 \% \mathrm{Fe}-\mathrm{TiO}_{2}$ & 0.07 & & & $7.00 \times 10^{-3}$ \\
\hline
\end{tabular}

The optical band gaps for the thin films are listed in Table 1. To estimate the band gap energies, the absorption onsets of the samples were determined by linear extrapolation from the inflection point of the curve to the baseline $[29,30]$. The band gap, $E_{g}$, was obtained from a linear regression of $(\alpha h \nu)^{1 / 2}$ against $h v$ with extrapolation to zero (Equation (1), often called a Tauc plot) [1,29-32]:

$$
(\alpha h \nu)^{1 / 2}=A\left(h \nu-E_{g}\right),
$$

where $\alpha$ is the absorbance, arbitrary units; $h \nu$ is photon energy, eV; $A$ is an independent parameter of the photon's energy for the respective transitions, $\mathrm{eV} ; E_{g}$ is the band gap, eV. Since the band gap of anatase was $3.2 \mathrm{eV}$, the results indicated that the structure of $\mathrm{TiO}_{2}$ in the thin film was indeed anatase. Increasing $\mathrm{Fe}^{3+}$ dopant concentration in $\mathrm{TiO}_{2}$ thin films greatly enhanced their absorption band and clearly narrowed the band gap from $3.27 \mathrm{eV}$ to $2.82 \mathrm{eV}$ and which was suitable for application as a catalyst in the photocatalytic process. A similar effect on the band gap has also been reported by several researchers, for example, Zhang et al. [33].

The 2D AFM images of the $\mathrm{TiO}_{2}$ and $\mathrm{Fe}-\mathrm{TiO}_{2}$ thin films on stainless steel substrate are shown in Figure 4. The data for surface morphology are summarized in Table 1. The grain sizes, the root mean square (rms) average roughness, 


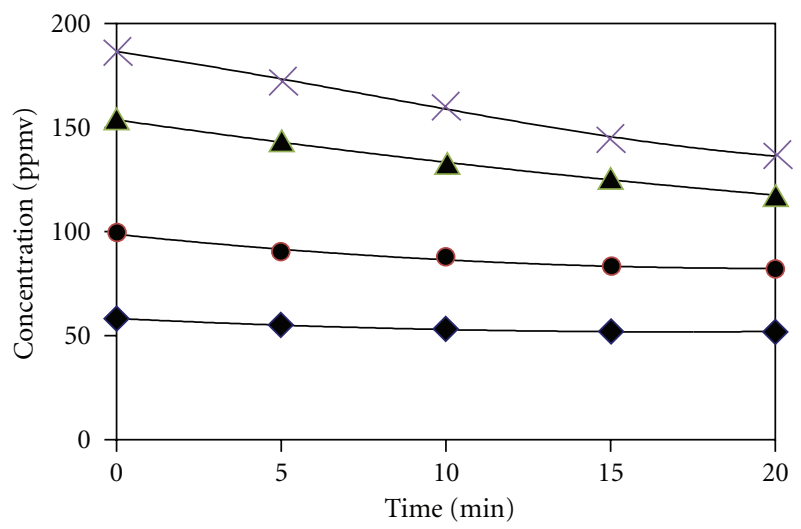

(a)

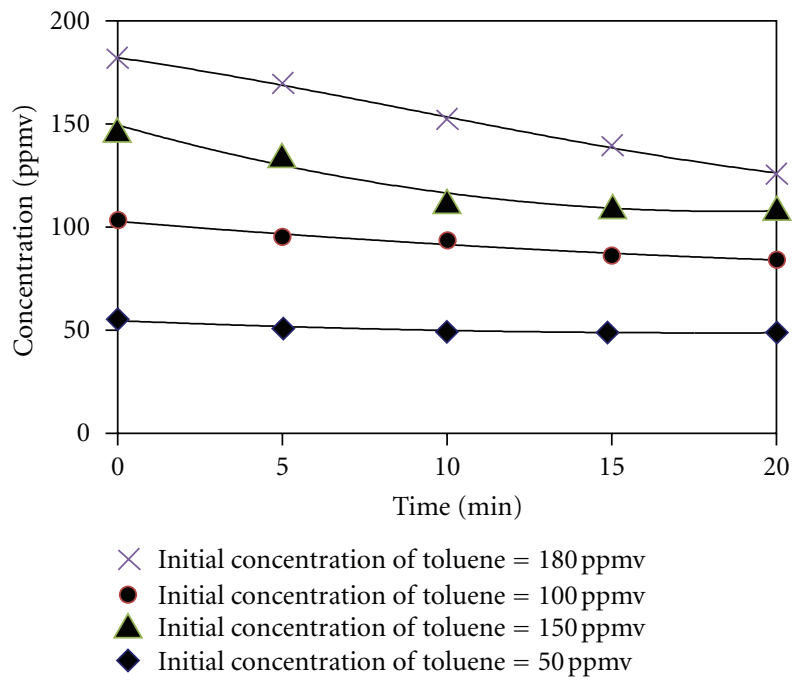

(c)

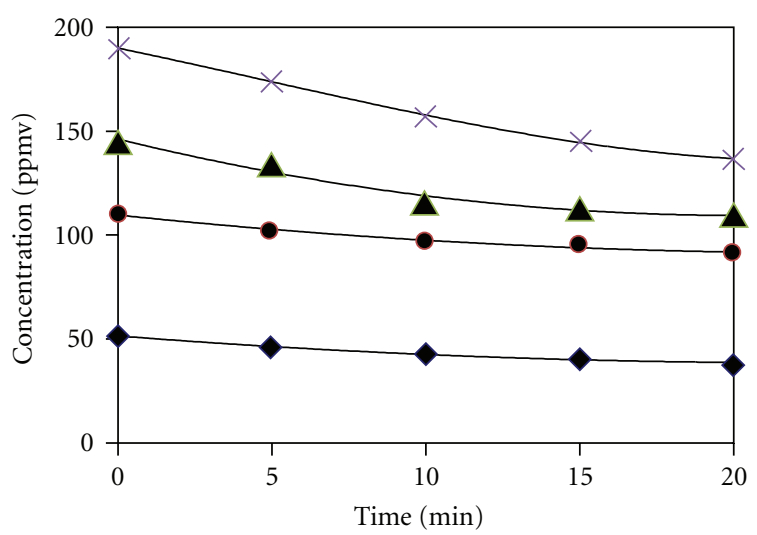

(b)

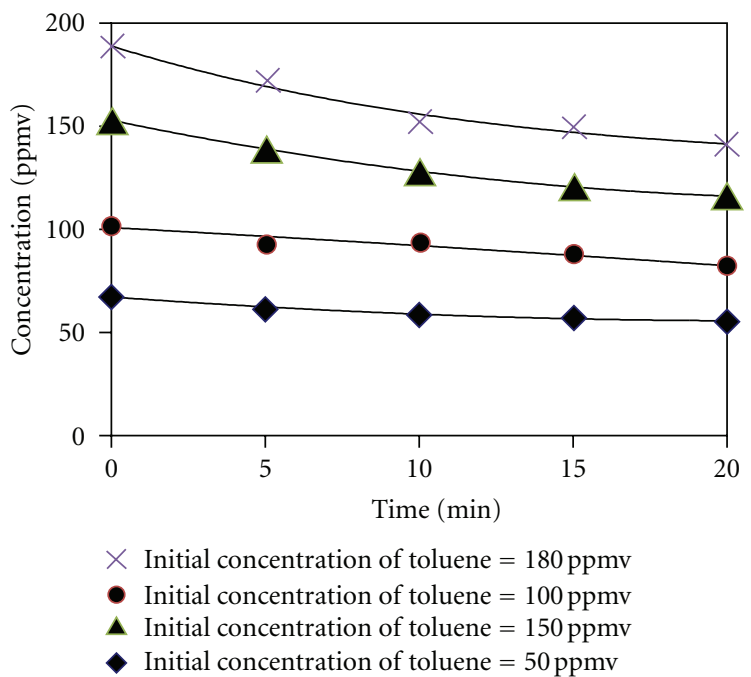

(d)

FIgure 5: Photocatalytic degradation of toluene with various $\mathrm{Fe}_{-} \mathrm{TiO}_{2}$ catalysts using UV-LED light source. (a) $\mathrm{TiO}_{2}$, (b) $0.3 \% \mathrm{Fe}-\mathrm{TiO}{ }_{2}$, (c) $0.5 \% \mathrm{Fe}-\mathrm{TiO}_{2}$, and (d) $0.7 \% \mathrm{Fe}-\mathrm{TiO}_{2}$.

and the apparent surface areas of all thin films were in the same range. However, the total apparent surface area per unit weight of $\mathrm{TiO}_{2}$ and the BET surface area tended to increase with the amount of $\mathrm{Fe}^{3+}$ added. The data indicated that the coating process used in this study could achieve a particle size of $30 \mathrm{~nm}$, a suggested optimum size for light absorption and scattering efficiencies [34].

Adhesion testing of all of the $\mathrm{TiO}_{2}$ thin films yielded a classification in class 4B (good adhesion) [21]. The results imply that the calcination temperature used in this study $\left(500^{\circ} \mathrm{C}\right)$ was sufficiently high to create good adhesion of $\mathrm{TiO}_{2}$ films on surfaces [35]. The corrosion-resistance test indicated that the $\mathrm{TiO}_{2}$ thin films could resist corrosion without any visible damage (Table 1).

3.2. Photocatalytic Activity of Toluene. A series of tests of photocatalytic degradation for various initial concentrations of toluene vapor with different catalysts evaluated the decomposition efficiency $(\eta)$ of toluene. The value of $\eta$ was calculated from

$$
\eta=\frac{\left(C_{0}-C\right)}{C_{0}} \times 100 \%,
$$

where $C_{0}$ is the initial concentration of toluene (ppmv) and $C$ is the concentration of toluene at time $t$ (ppmv). The photocatalytic degradation of toluene according to the initial concentration is shown in Figure 5.

The data showed that the $\mathrm{Fe}-\mathrm{TiO}_{2}$ catalyst was more active than $\mathrm{TiO}_{2}$ alone. It indicated that this modification could promote the activity of the $\mathrm{TiO}_{2}$ catalyst to a certain extent, since the $\mathrm{Fe}^{3+}$ ions created more chance to generate electron-hole pairs. Consequently, the amount of hydroxyl radicals $\left({ }^{\circ} \mathrm{OH}\right)$, which are highly oxidative species in the photocatalytic oxidation reaction, would increase $[11,36]$. Therefore, the photocatalytic activity could be improved by increasing the $\mathrm{Fe}^{3+}$ dopant concentration $[33,37]$. The improvement in the photoactivity could be caused by 


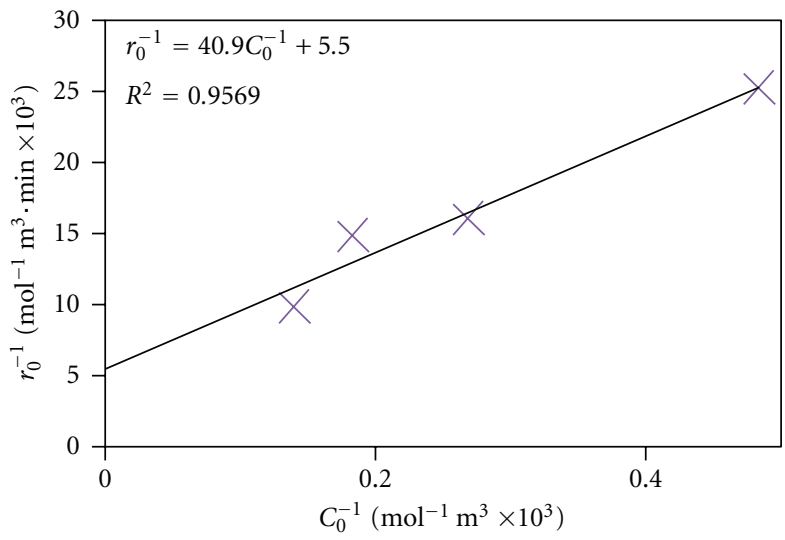

(a)

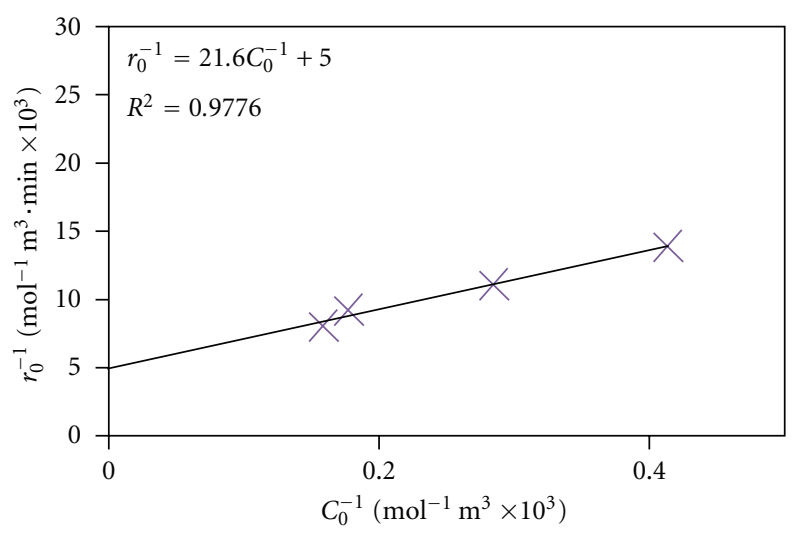

(c)

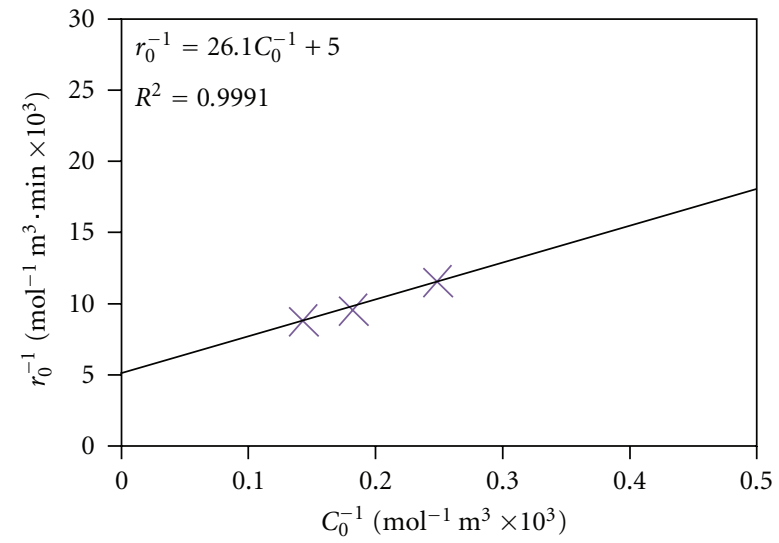

(b)



(d)

Figure 6: L-H plots of $r_{0}^{-1}$ versus $C_{0}^{-1}$ for toluene with various $\mathrm{Fe}-\mathrm{TiO}_{2}$ catalysts using a UV-LED light source. (a) $\mathrm{TiO}_{2}$, (b) $0.3 \% \mathrm{Fe}-\mathrm{TiO}$, (c) $0.5 \% \mathrm{Fe}-\mathrm{TiO}_{2}$, and (d) $0.7 \% \mathrm{Fe}-\mathrm{TiO}_{2}$.

the combined effects of the crystalline structure, the optical band gap, grain size, and the surface area of the catalyst [38-42]. The photocatalytic degradation efficiency of Fe$\mathrm{TiO}_{2}$ thin films increased and reached a maximum when the $\mathrm{Fe}^{3+}$ dopant concentration was $0.7 \%$. Piera et al. [38] and Khan et al. [43] showed that the $\mathrm{Fe}^{3+}$ ions in $\mathrm{TiO}_{2}$ thin films were responsible for a reduction in the photogenerated hole-electron recombination rate. This corresponded to the reduction in the optical band gaps of the $\mathrm{Fe}-\mathrm{TiO}_{2}$ thin films. The active sites in the $\mathrm{Fe}-\mathrm{TiO}_{2}$ thin film could effectively capture the electrons and prolong the lifetime of photogenerated charges, thereby increasing the efficiency of charge separation and transfer of $\mathrm{Fe}-\mathrm{TiO}_{2}$ [44]. It is believed that the efficiency of a photocatalyst depends on quantum efficiency of the photo generation of the electron-hole pair $[33,44]$. Moreover, the degradation rate of toluene by the $\mathrm{Fe}-\mathrm{TiO}_{2}$ films can be enhanced due to increased surface area [36]. In this study, the maximum concentration of $\mathrm{Fe}^{3+}$ dopant of $0.7 \%$ showed the highest photocatalytic activity.

The kinetic modeling of the photocatalytic process followed the Langmuir-Hinshelwood model (L-H model), which can be expressed as [45]

$$
r=\frac{k K C}{(1+K C)}
$$

where $k$ is the reaction rate constant $\left(\mathrm{mol} \cdot \mathrm{m}^{-3} \cdot \mathrm{min}^{-1}\right), K$ is the adsorption equilibrium constant $\left(\mathrm{m}^{3} \cdot \mathrm{mol}^{-1}\right)$, and $C$ is the concentration of toluene $\left(\mathrm{mol} \cdot \mathrm{m}^{-3}\right)$. This model usually analyzed the initial rate of photocatalytic degradation. The initial photocatalytic degradation rate, $r_{0},\left(\mathrm{~mol} \cdot \mathrm{m}^{-3} \cdot \mathrm{min}^{-1}\right)$ is observed to be a function of the initial concentration of toluene $\left(C_{0}\right)$. According to (4), a linear $\mathrm{L}-\mathrm{H}$ plot of $r_{0}^{-1}$ versus $C_{0}^{-1}$ is obtained and the $\mathrm{L}-\mathrm{H}$ rate constant, $k$, and the Langmuir adsorption constant, $K$, of toluene in the photocatalytic degradation reaction can be calculated:

$$
\frac{1}{r_{0}}=\frac{1}{k K C_{0}}+\frac{1}{k} .
$$

The L-H plots of $r_{0}^{-1}$ versus $C_{0}^{-1}$ for toluene with various $\mathrm{Fe}-\mathrm{TiO}_{2}$ catalysts using a UV-LED light source are shown in Figure 6 . The kinetic parameters $k$ and $K$ of the photocatalytic degradation reaction are summarized in Table 2.

The effect of toluene concentration on toluene degradation with a UV-LED light source and $\mathrm{TiO}_{2}$ thin films could be well defined by the L-H kinetic equation. The results of the overall photocatalytic degradation efficiency of this study are quite low, between $13.56 \%$ and $36.51 \%$ within $60 \mathrm{~min}$. This could be mainly due to the UV-LED light source 
used in our experiments providing a UV-light intensity of only $1000 \mathrm{~mW} \cdot \mathrm{m}^{-2}$. In terms of the photocatalytic kinetic constants, both the reaction rate constant $(k)$ and the adsorption equilibrium constant $(K)$ increased with increasing concentration of $\mathrm{Fe}^{3+}$ dopant (Table 2). When comparing the kinetics results from this study to those of other studies using different light intensities and a similar catalyst for toluene degradation, we found that the values of the overall reaction rate constants, $k K$, from this study were lower than those of Kim and Hong [20] for $\mathrm{TiO}_{2}$ catalyst, but were comparable to those of Shie and Pai [19] for $\mathrm{Ag} / \mathrm{TiO}_{2}$ catalyst (Table 3). However, the specific rates calculated in this study were around $10^{-3} \mathrm{~min}^{-1} \cdot \mathrm{mW}^{-1}$, which is about one to two orders of magnitude higher than those in the other studies (Table 3 ). The results indicated that the enhanced activity of the photocatalytic process using $\mathrm{Fe}^{3+}$ could potentially be applied for photocatalytic degradation of VOCs using a UVLED light source. This indicated that, in further applications, the degradation efficiency can be improved by increasing the surface area coating of the photocatalyst, increasing the intensity of the UV-LED light source, and reducing the distance between the light source and catalyst.

\section{Conclusions}

The prepared $\mathrm{TiO}_{2}$ and $\mathrm{Fe}-\mathrm{TiO}_{2}$ thin films had desirable physical properties including anatase crystalline structure, nano-sized grains, good mechanical stability, and good corrosion resistance and could be suitable catalysts in various photocatalytic processes. Increasing the $\mathrm{Fe}$-doping amount in $\mathrm{TiO}_{2}$ thin films decreased the optical band gaps and enhanced the performance of the photocatalytic process under UV-LED light irradiation. The photocatalytic degradation efficiency of toluene increased as the amount of $\mathrm{Fe}^{3+}$ dopant increased and reached its maximum efficiency at $0.7 \%$. The values of the reaction rate constants from this study are in the order of $10^{-3} \mathrm{~min}^{-1} \cdot \mathrm{mW}^{-1}$ with specific rates in the range of $2.00 \times 10^{-3}-7.00 \times 10^{-3} \mathrm{~min}^{-1} \cdot \mathrm{mW}^{-1}$.

\section{Acknowledgments}

This work was funded by research grants from the Kasetsart University Research and Development Institute (KURDI), the Center of Advanced Studies in Industrial Technology, Faculty of Engineering, Kasetsart University and the Graduate Division, Graduate School, Kasetsart University, Bangkok, Thailand.

\section{References}

[1] J. S. Im, S. M. Yun, and Y. S. Lee, "Investigation of multielemental catalysts based on decreasing the band gap of titania for enhanced visible light photocatalysis," Journal of Colloid and Interface Science, vol. 336, no. 1, pp. 183-188, 2009.

[2] M. H. Habibi, M. N. Esfahani, and T. A. Egerton, "Photochemical characterization and photocatalytic properties of a nanostructure composite $\mathrm{TiO}_{2}$ Film," International Journal of Photoenergy, vol. 2007, Article ID 13653, 8 pages, 2007.
[3] S. S. Pradhan, S. Sahoo, and S. K. Pradhan, "Influence of annealing temperature on the structural, mechanical and wetting property of $\mathrm{TiO}_{2}$ films deposited by RF magnetron sputtering," Thin Solid Films, vol. 518, no. 23, pp. 6904-6908, 2010.

[4] L. Ying, C. Shuo, Q. Xie, and Y. Hongtao, "Fabrication of a $\mathrm{TiO}_{2} / \mathrm{Au}$ nanorod array for enhanced photocatalysis," Chinese Journal Catalysis, vol. 32, no. 12, pp. 1838-1843, 2011.

[5] M. Ma, Y. Li, W. Chen, and L. Li, "Preparation of cost-effective $\mathrm{TiO}_{2}$-outerloaded porous lava composites using supercritical $\mathrm{CO}_{2}$ and their photocatalytic activity for methylene blue degradation," Chinese Journal of Catalysis, vol. 31, no. 10, pp. 1221-1226, 2010.

[6] A. P. Xagas, E. Androulaki, A. Hiskia, and P. Falaras, "Preparation, fractal surface morphology and photocatalytic properties of $\mathrm{TiO}_{2}$ films," Thin Solid Films, vol. 357, no. 2, pp. 173-178, 1999.

[7] X. Chen, "Titanium dioxide nanomaterials and their energy applications," Chinese Journal of Catalysis, vol. 30, no. 8, pp. 839-851, 2009.

[8] R. Yuanhang, G. Min, H. Yichen et al., "Preparation and photocatalytic activity of lanthanide loaded microporous titanosilicate ETS-10 catalysts," Chinese Journal Catalysis, vol. 33, no. 1, pp. 123-128, 2012.

[9] A. Eshaghi, R. Mozaffarinia, M. Pakshir, and A. Eshaghi, "Photocatalytic properties of $\mathrm{TiO}_{2}$ sol-gel modified nanocomposite films," Ceramics International, vol. 37, no. 1, pp. 327-331, 2011.

[10] Z. Wang, L. Shen, and S. Zhu, "Synthesis of core-shell $\mathrm{Fe}_{3} \mathrm{O}_{4} @ \mathrm{SiO}_{2} @ \mathrm{TiO}_{2}$ microspheres and their application as recyclable photocatalysts," International Journal of Photoenergy, vol. 2012, Article ID 202519, 2012.

[11] J. A. Byrne, P. A. Fernandez-Ibañez, P. S. M. Dunlop, D. M. A. Alrousan, and J. W. J. Hamilton, "Photocatalytic enhancement for solar disinfection of water: a review," International Journal of Photoenergy, vol. 2011, Article ID 798051, 12 pages, 2011.

[12] J. Yu, M. Jaroniec, and G. $\mathrm{Lu}$, "TiO 2 photocatalytic materials," International Journal of Photoenergy, vol. 2012, Article ID 206183, 5 pages, 2012.

[13] G. Balasubramanian, D. D. Dionysiou, and M. T. Suidan, "Titanium dioxide coatings on stainless steel," in Dekker Encyclopedia of Nanoscience and Nanotechnology, p. 9, Marcel Dekker, 2004.

[14] Y. Chen and D. D. Dionysiou, "Effect of calcination temperature on the photocatalytic activity and adhesion of $\mathrm{TiO}_{2}$ films prepared by the P-25 powder-modified sol-gel method," Journal of Molecular Catalysis A, vol. 244, no. 1-2, pp. 73-82, 2006.

[15] M. M. Hasan, A. S. M. A. Haseeb, H. H. Masjuki, and R. Saidur, "Adhesion and wear behavior of nanostructured titanium oxide thin films," International Journal of Mechanical and Materials Engineering, vol. 5, no. 1, pp. 5-10, 2010.

[16] S. H. Nam, S. J. Cho, C. K. Jung et al., "Comparison of hydrophilic properties of $\mathrm{TiO}_{2}$ thin films prepared by sol-gel method and reactive magnetron sputtering system," Thin Solid Films, vol. 519, pp. 6944-6950, 2011.

[17] T. C. Cheng, K. S. Yao, N. Yeh et al., "Bactericidal effect of blue LED light irradiated $\mathrm{TiO}_{2} / \mathrm{Fe}_{3} \mathrm{O}_{4}$ particles on fish pathogen in seawater," Thin Solid Films, vol. 519, no. 15, pp. 5002-5006, 2011.

[18] L. H. Levine, J. T. Richards, R. Soler, F. Maxik, J. Coutts, and R. M. Wheeler, "Feasibility of ultraviolet light emitting diodes as an alternative light source for photocatalysis," Journal of the Air 
\& Waste Management Association, vol. 61, no. 9, pp. 932-940, 2011.

[19] J. L. Shie and C. Y. Pai, "Photodegradation kinetics of toluene in indoor air at different humidities using UVA, UVC and UVLED light sources in the presence of silver titanium dioxide," Indoor and Built Environment, vol. 19, no. 5, pp. 503512, 2010.

[20] S. B. Kim and S. C. Hong, "Kinetic study for photocatalytic degradation of volatile organic compounds in air using thin film $\mathrm{TiO}_{2}$ photocatalyst," Applied Catalysis B, vol. 35 , no. 4, pp. 305-315, 2002.

[21] “ASTM Standard D3359-08," in ASTM International, West Conshohocken, Pa, USA, 2008.

[22] A. K. Shankar, V. R. Raju, M. N. Rao, U. K. Mudali, H. S. Khatak, and B. Raj, "Corrosion of Zircaloy-4 and its welds in nitric acid medium," Corrosion Science, vol. 49, no. 9, pp. 3527-3538, 2007.

[23] A. Eshaghi, M. Pakshir, and R. Mozaffarinia, "Preparation and characterization of $\mathrm{TiO}_{2}$ sol-gel modified nanocomposite films," Journal of Sol-Gel Science and Technology, vol. 55, no. 3, pp. 278-284, 2010.

[24] L. Zhao, J. Ran, Z. Shu, G. Dai, P. Zhai, and S. Wang, "Effects of calcination temperatures on photocatalytic activity of ordered titanate Nanoribbon $/ \mathrm{SnO}_{2}$ films fabricated during an EPD process," International Journal of Photoenergy, vol. 2012, Article ID 472958, 7 pages, 2012.

[25] V. G. Bessergenev, M. C. Mateus, D. A. Vasconcelos et al., " $\mathrm{TiO}_{2}$ :(Fe, S) thin films prepared from complex precursors by CVD, physical chemical properties, and photocatalysis," International Journal of Photoenergy, vol. 2012, Article ID 767054, 12 pages, 2012.

[26] J. Yu, Q. Xiang, and M. Zhou, "Preparation, characterization and visible-light-driven photocatalytic activity of Fe-doped titania nanorods and first-principles study for electronic structures," Applied Catalysis B, vol. 90, no. 3-4, pp. 595-602, 2009.

[27] Z. Xu and J. Yu, "Visible-light-induced photoelectrochemical behaviors of Fe-modified $\mathrm{TiO}_{2}$ nanotube arrays," Nanoscale, vol. 3, pp. 3138-3144, 2011.

[28] R. Mechiakh, N. B. Sedrine, R. Chtourou, and R. Bensaha, "Correlation between microstructure and optical properties of nano-crystalline $\mathrm{TiO}_{2}$ thin films prepared by sol-gel dip coating," Applied Surface Science, vol. 257, no. 3, pp. 670-676, 2010.

[29] E. Barajas-Ledesma, M. L. García-Benjume, I. Espitia-Cabrera et al., "Determination of the band gap of $\mathrm{TiO}_{2}-\mathrm{Al}_{2} \mathrm{O}_{3}$ films as a function of processing parameters," Materials Science and Engineering B, vol. 174, no. 1-3, pp. 71-73, 2010.

[30] L. Ge, M. Xu, and H. Fang, "Photo-catalytic degradation of methyl orange and formaldehyde by $\mathrm{Ag} / \mathrm{InVO}^{4}-\mathrm{TiO}_{2}$ thin films under visible-light irradiation," Journal of Molecular Catalysis A, vol. 258, no. 1-2, pp. 68-76, 2006.

[31] V. Augugliaro, V. Loddo, G. Palmisano, L. Palmisano, and M. Pagliaro, Clean by Light Irradiation Practical Applications of Supported $\mathrm{TiO}_{2}$, The Royal Society of Chemistry, Cambridge, UK, 2010.

[32] A. B. Murphy, "Band-gap determination from diffuse reflectance measurements of semiconductor films, and application to photoelectrochemical water-splitting," Solar Energy Materials and Solar Cells, vol. 91, no. 14, pp. 1326-1337, 2007.

[33] Y. Zhang, Y. Shen, F. Gu, M. Wu, Y. Xie, and J. Zhang, "Influence of Fe ions in characteristics and optical properties of mesoporous titanium oxide thin films," Applied Surface Science, vol. 256, no. 1, pp. 85-89, 2009.

[34] C. B. Almquist and P. Biswas, "Role of synthesis method and particle size of nanostructured $\mathrm{TiO}_{2}$ on its photoactivity," Journal of Catalysis, vol. 212, no. 2, pp. 145-156, 2002.

[35] J. Yu, H. Yu, C. H. Ao, S. C. Lee, J. C. Yu, and W. Ho, "Preparation, characterization and photocatalytic activity of in situ Fe-doped $\mathrm{TiO}_{2}$ thin films," Thin Solid Films, vol. 496, no. 2, pp. 273-280, 2006.

[36] Q. Xiang, J. Yu, and P. K. Wong, "Quantitative characterization of hydroxyl radicals produced by various photocatalysts," Journal of Colloid and Interface Science, vol. 357, no. 1, pp. 163167, 2011.

[37] Q. Yu, C. Zhou, and X. Wang, "Influence of plasma spraying parameter on microstructure and photocatalytic properties of nanostructured $\mathrm{TiO}_{2}-\mathrm{Fe}_{3} \mathrm{O}_{4}$ coating," Journal of Molecular Catalysis A, vol. 283, no. 1-2, pp. 23-28, 2008.

[38] E. Piera, M. I. Tejedor-Tejedor, M. E. Zorn, and M. A. Anderson, "Relationship concerning the nature and concentration of $\mathrm{Fe}(\mathrm{III})$ species on the surface of $\mathrm{TiO}_{2}$ particles and photocatalytic activity of the catalyst," Applied Catalysis B, vol. 46, no. 4, pp. 671-685, 2003.

[39] N. J. Kim, Y. H. La, S. H. Im, and B. K. Ryu, "Optical and structural properties of $\mathrm{Fe}-\mathrm{TiO}_{2}$ thin films prepared by sol-gel dip coating," Thin Solid Films, vol. 518, no. 24, pp. e156-e160, 2010.

[40] X. Lu, Y. Ma, B. Tian, and J. Zhang, "Preparation and characterization of $\mathrm{Fe}-\mathrm{TiO}_{2}$ films with high visible photoactivity by autoclaved-sol method at low temperature," Solid State Sciences, vol. 13, no. 3, pp. 625-629, 2011.

[41] D. Klauson and S. Preis, "The influence of iron ions on the aqueous photocatalytic oxidation of deicing agents," International Journal of Photoenergy, vol. 2007, Article ID 89359, 7 pages, 2007.

[42] M. S. A. Abdel-Mottaleb, V. Augugliaro, and L. Palmisano, "Doped $\mathrm{TiO}_{2}$ nanomaterials and applications," International Journal of Photoenergy, vol. 2008, Article ID 419096, 1 pages, 2008.

[43] R. Khan, S. W. Kim, T. J. Kim, and C. M. Nam, "Comparative study of the photocatalytic performance of boron-iron Co-doped and boron-doped $\mathrm{TiO}_{2}$ nanoparticles," Materials Chemistry and Physics, vol. 112, no. 1, pp. 167-172, 2008.

[44] S. Sun, J. Ding, J. Bao et al., "Photocatalytic degradation of gaseous toluene on $\mathrm{Fe}-\mathrm{TiO}_{2}$ under visible light irradiation: a study on the structure, activity and deactivation mechanism," Applied Surface Science, vol. 258, pp. 5031-5037, 2012.

[45] J. Yu, M. Zhou, H. Yu, Q. Zhang, and Y. Yu, "Enhanced photoinduced super-hydrophilicity of the sol-gel-derived $\mathrm{TiO} 2$ thin films by Fe-doping," Materials Chemistry and Physics, vol. 95, no. 2-3, pp. 193-196, 2006. 


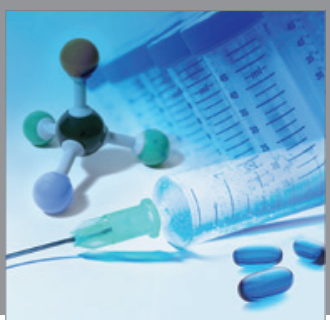

International Journal of

Medicinal Chemistry

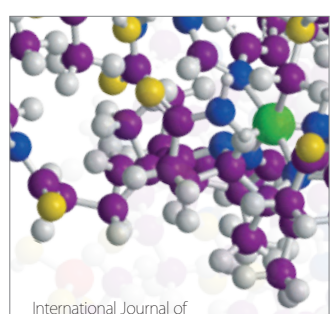

Carbohydrate Chemistry

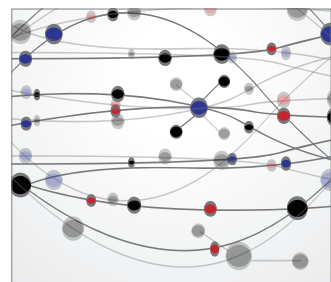

The Scientific World Journal
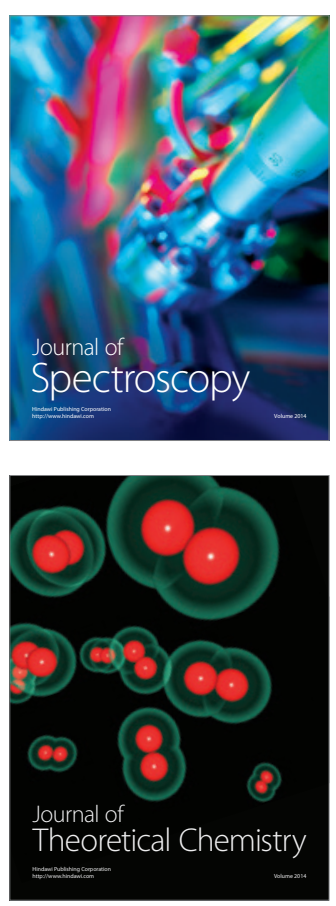
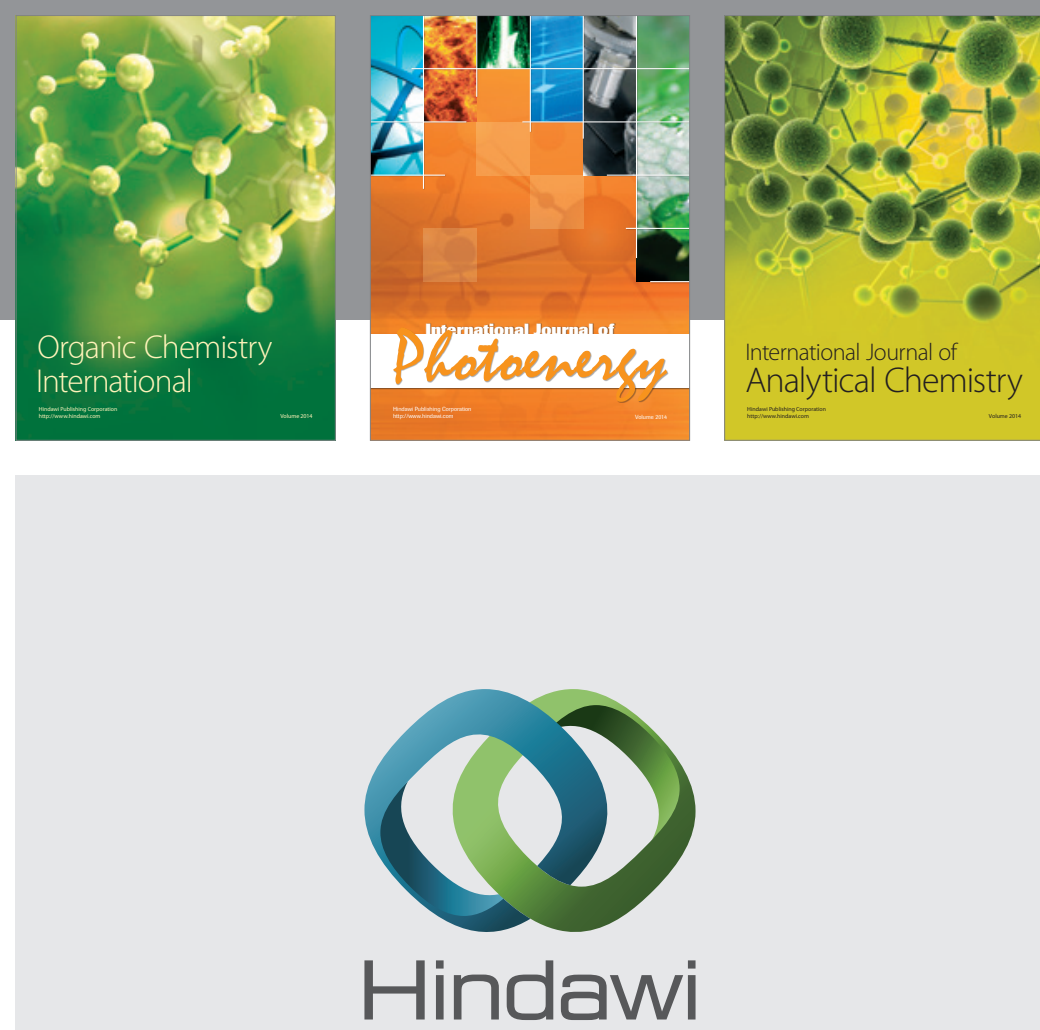

Submit your manuscripts at

http://www.hindawi.com
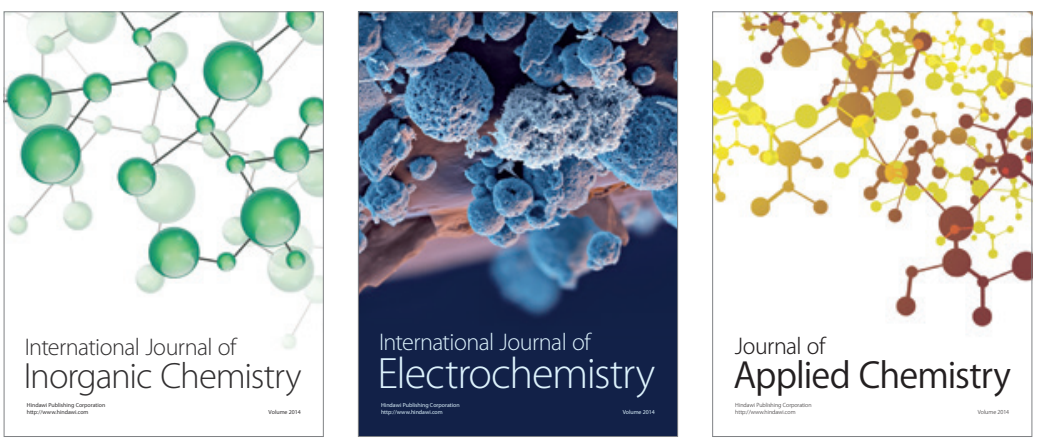

Journal of

Applied Chemistry

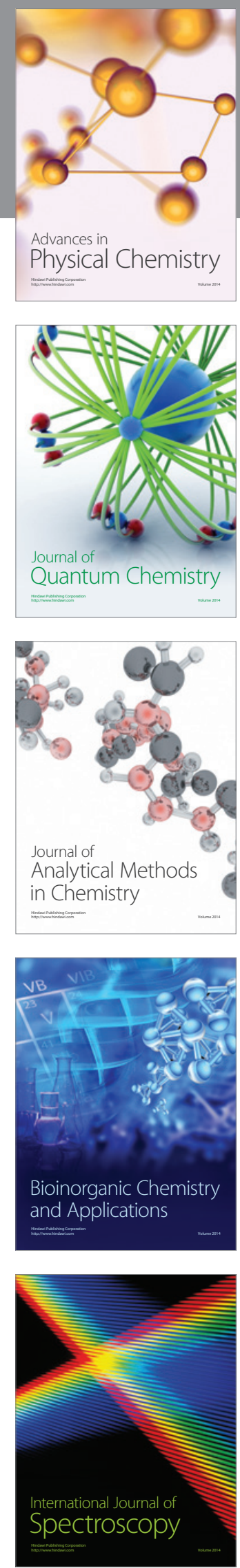